\title{
Arthrogryposis Accompanying Congenital Spinal-type Muscular Atrophy
}

\author{
MICHAEL BESSER * and ALBERT BEHAR \\ From the Department of Pathology, the Rothschild-Hadassah University Hospital, and \\ the Hebrew University-Hadassah Medical School, Jerusalem, Israel
}

Arthrogryposis is a congenital condition in which multiple skeletal deformities of the extremities and spine are caused by fibrosis and contractures of skeletal muscles accompanying a neurogenic atrophy (Brandt, 1947; Kanof, Aronson, and Volk, 1956; Bargeton, Nezelof, Guran, and Job, 1961 ; Vestermark, 1966) or a primary myopathy (Thamdrup, 1955; Banker, Victor, and Adams, 1957) acquired in utero. This condition is often seen together with many other congenital anomalies (Katzeff, 1943; Moncrieff and Wiles, 1934), and a hereditary or familial incidence (Swinyard, 1960) has been recorded. Its aetiology is entirely obscure. For a concise review of the published reports on the subject the reader is referred to the monograph on diseases of the muscle by Adams, Denny-Brown, and Pearson (1962).

The paucity of reported cases of arthrogryposis in which the spinal cord was examined histologically (only three such cases are cited in the above mentioned monograph) has prompted us to present the following.

\section{Clinical History}

This infant was born by premature labour, after seven and a half months' pregnancy, and lived for only a few minutes.

The pregnancy, the mother's first, was normal and there was no history of drug taking or illnesses.

The father was healthy and there was no family history of congenital abnormalities and illnesses.

A complete necropsy was performed seven hours after death.

\section{Necropsy}

Premature baby. Partially non-aerated lungs.

Congenital heart disease with preductal coarctation of aorta (infantile type) combined with hypoplasia of ascending aorta and overriding of ventricular septum by pulmonary artery, unusually wide patent ductus arteriosus, and closed foramen ovale.

\footnotetext{
Received January 26, 1967.

* Present address: Accident and Emergency Department, King's College Hospital, London, S.E. 5.
}

Severely malformed genito-urinary system, with dysplastic polycystic horseshoe kidney, megacyst and megaureter, hydronephrosis, right-sided urachal cyst, hypospadias, and intra-abdominal testes.

Congenital scoliosis with dislocated hips and bilateral genu recurvatum, bilateral pes equinovarus and bilateral club hands (Fig. 1).

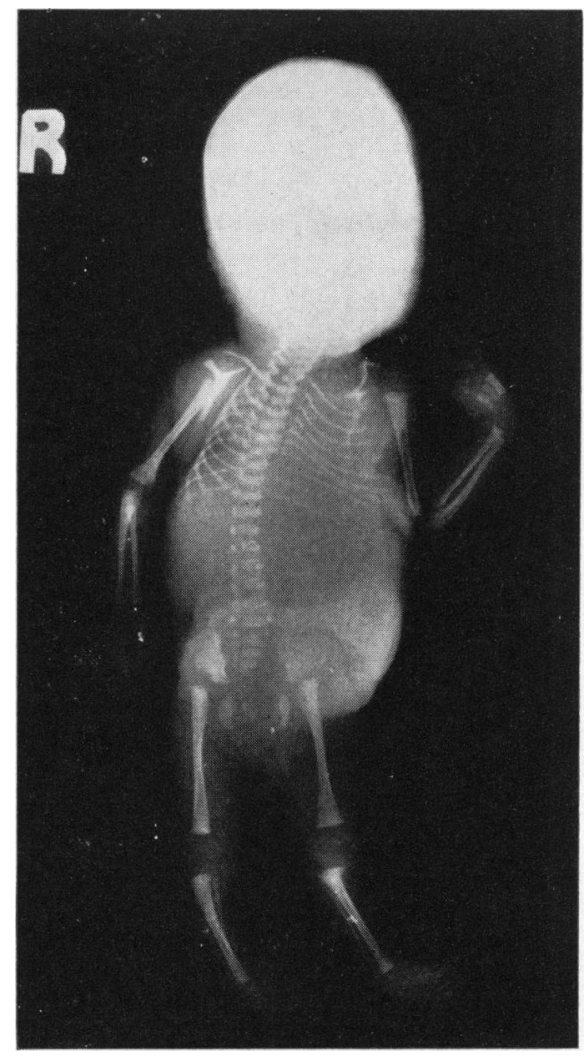

Fig. 1.-X-ray film showing congenital scoliosis, bilateral congenital dislocated hips, bilateral club hands and club feet, and bilateral genu recurvatum. 


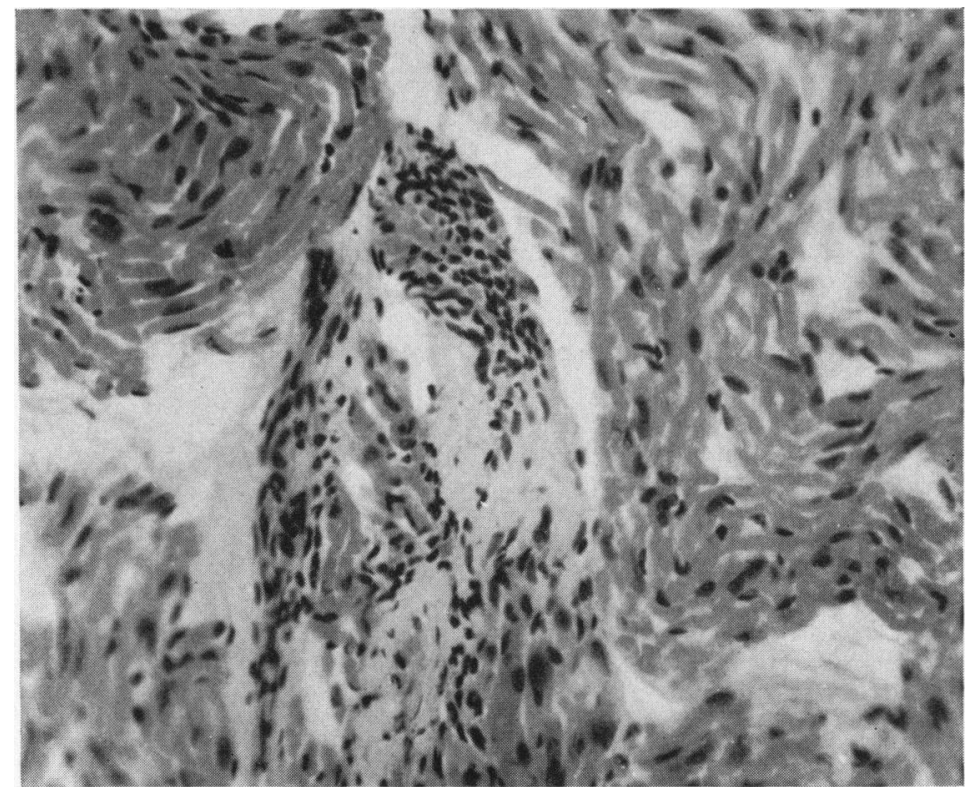

Fig. 2.-Sample from left triceps muscle showing 'large groups of small fibres (centre)'. (H. and E. $\times 270$.)

In addition, Meckel's diverticulum; absence of earlobes.

Skeletal muscles. Macroscopically, muscles showed a distinct pallor with whitish streaks in some areas. Some, like the gemelli, were quite white and showed no likeness to muscular tissue.

Histologically, the left triceps of the arm showed uniformly thin fibres, arranged in a normal architectural pattern. There were, however, scattered 'large groups of small fibres' in which the fibre diameter was about one-half, or less, than that of the surrounding muscle fibres (Fig. 2). In some areas the atrophy involved whole primary and secondary fibre groups, with a considerable amount of endo- and perimysial fibrosis as well as fibrous replacement of muscle tissue.

The right triceps of the arm showed no 'large groups of small fibres'; however, there was an increase in endomysial fibrous tissue which was often oedematous. In capillaries many nucleated red cells were seen.

The left biceps showed muscle fibres which, on the whole, were of small uniform size, arranged in a normal histological pattern, with larger than normal spaces between the secondary groupings and with a marked amount of interstitial oedema. Throughout the whole section there were seen 'many large groups of small fibres', with a moderate degree of fibrosis.

The contralateral biceps showed a similar picture.

The left extensor group of forearm, except for small areas in which muscle fibres looked more or less of a normal size for the age of the patient, consisted of atrophic fibres of uniform size arranged in a normal histological pattern. There were fairly large areas of fibrosis in which small groups of very atrophic muscle fibres were embedded. The right forearm extensor group had a similar histological picture.

The right forearm flexor group showed severe changes due to the atrophy of the type described in the other muscles, as well as extensive collagenous fibrosis.

The right hamstrings showed the same type of changes as described in the upper extremities, but the fibrosis was moderate.

Right gastrocnemius, right quadriceps, and right dorsiflexors all showed histological changes similar to those already described above.

The changes in the gemelli were of the above type, but of an exceptionally high degree, most of the muscle being replaced by fibrous collagenous tissue (Fig. 3). In the areas in which the muscle was still preserved, the fibres were uniformly thin, but among them, groups of exceptionally thin fibres could be discerned.

In none of the muscles examined was there inflammation of any kind. In many of them muscle spindles showed marked capsular 'onion-skin' fibrosis with atrophy of intrafusal fibres (Fig. 4).

Central nervous system. Macroscopically, the leptomeninges were smooth and glistening. Several ecchymosal haemorrhages, apparently fresh, were seen on the surface of the cerebrum. The cortical external configuration appeared normal except for the anterior halves of the temporal lobes where the convolutions were fewer and broader than normal.

Sections through the cerebrum, the brain-stem, and the cerebellum did not show any changes. 


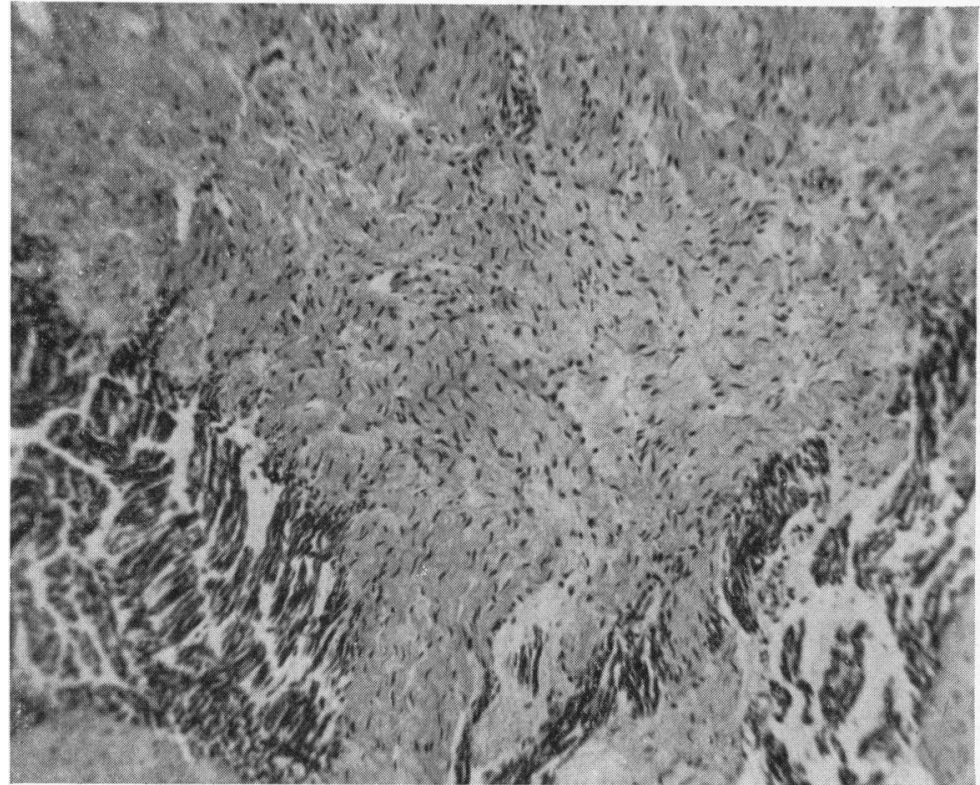

FIG. 3.-Sample from gemellus muscle, showing extensive fibrosis with replacement of muscle tissue. (Trichrome $\times 110$.)

Histologically, the sections of different areas of the cerebral cortex showed a normal cyto-architecture and mild non-specific hypoxic changes. The pre-central gyri showed paucity of large motor (Betz) nerve cells.
Sections from the brain-stem appeared normal. In the cerebellum the external granular layer was still present.

Multiple sections from various levels of the spinal cord showed presence of many neurones at the peripheral

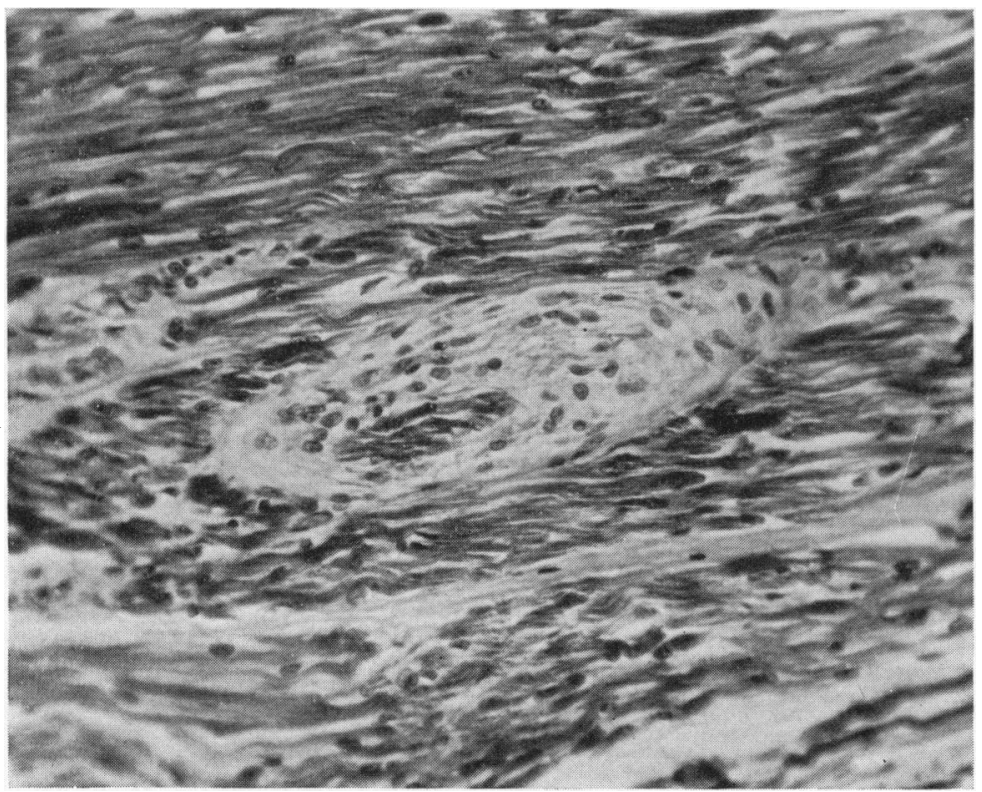

Fig. 4.-Muscle spindle with eccentric fibrosis of capsule and atrophy of intrafusal muscle fibres.

(H. and E. $\times 270$. 


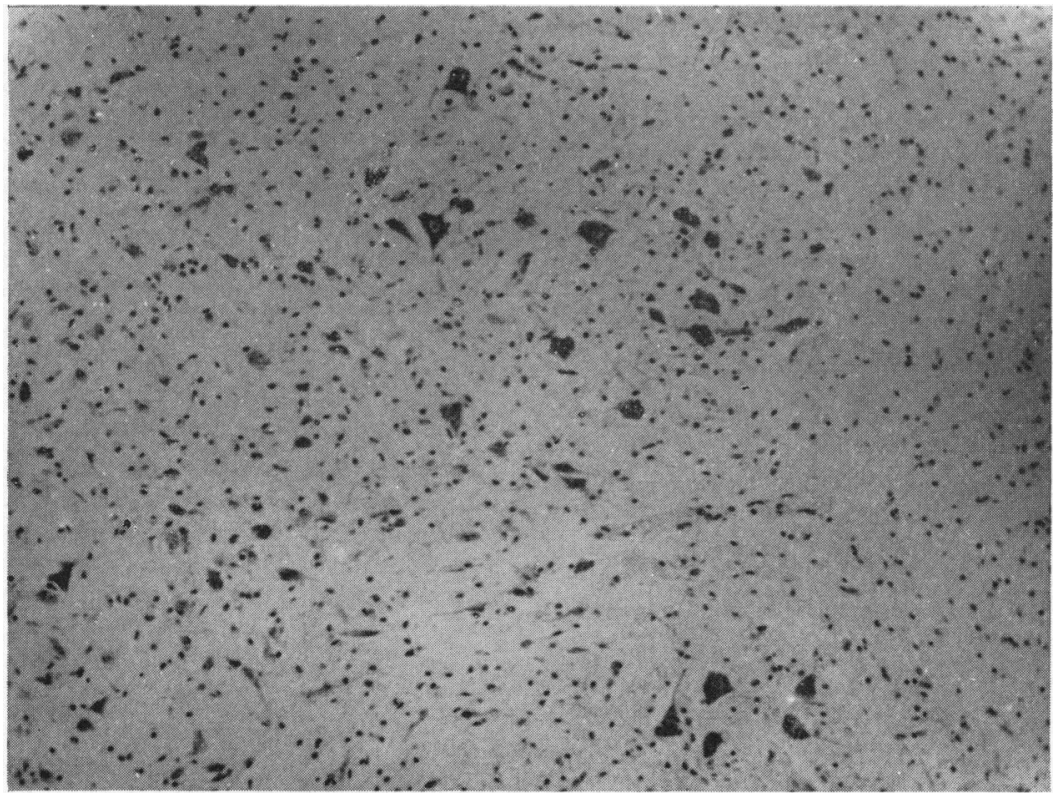

FIG. 5.-Ventral portion of anterior horn, showing absence of nerve cells. $($ Nissel $\times 110$.

borders of the ventral horns as well as in the intermediolateral columns and Clark's columns: however, in most of the central areas of the ventral grey columns there was a marked absence of neurones (Fig. 5) and a considerable increase in the number of glial cells, particularly microglia.

Sections of spinal nerves showed a variety of pictures; when stained for myelin some nerves were well and uniformly myelinated whereas others were almost completely devoid of myelin.

\section{Discussion}

It is at present believed that arthrogryposis is secondary either to a spinal-type muscular atrophy (Brandt, 1947; Vestermark, 1966; Kanof et al., 1956; Bargeton et al., 1961; Adams et al., 1962) or a primary myopathy (Thamdrup, 1955; Banker et al., 1957; Adams et al., 1962), both of them of unknown aetiology. In the neurogenic type, a congenital absence, or reduction in number, of anterior horn neurones has been invariably described in those very few cases in which the spinal cord was examined (Adams et al., 1962; Blattner, 1966). In the myopathic form, the muscle disease presented clinically as amyotonia with atrophy, and histologically showed the recognizable features of primary muscular dystrophy. However, we very recently had the opportunity of examining, through the courtesy of Professor Erich Liban, histological sections from many skeletal muscles in a typical case of arthrogryopsis. The muscles showed absolutely no abnormalities, and since this was associated with a severe gross depletion of skeletal muscle mass, it suggested the diagnosis of universal muscular hypoplasia. Arthrogryposis may, apparently, result from a variety of congenital pathological conditions of the skeletal musculature (James, 1951).

The histological changes of the muscles in our case can explain the associated skeletal deformities such as club hands, club feet, scoliosis genu recurvatum, and congenital dislocated hip. In the latter deformity release of the fibrotic gemelli from the joint capsule and greater trochanter during the necropsy allowed reduction of the dislocation without any difficulty, thus suggesting an alternative method for surgical reduction of this condition (Ch. Weinberg, 1966, personal communication).

\section{Summary}

A case of arthrogryposis with full necropsy is presented, in which the central nervous system and many muscles of the four extremities were examined histologically. The cerebrum showed scarcity of large pyramidal (Betz) cells in the pre-central gyri, the spinal cord showed a 'fall-out' of many anterior horn neurones, whereas in skeletal muscles the histology was compatible with spinal type muscular atrophy with extensive fibrosis. 
The aetiology of the pathological changes in arthrogryposis remains unknown.

The authors wish to express their appreciation to Professor Erich Liban for kindly letting them examine his case; and to Professor Henry Ungar for reviewing the manuscript.

\section{REFERENCES}

Adams, R. D., Denny-Brown, D., and Pearson, C. M. (1962). Diseases of the Muscle. A Study in Pathology, 2nd ed., p. 310. Hoeber, New York.

Amick, L. D., Johnson, W. W., and Smith, H. L. (1967). Arthrogryposis. Arch. Neurol. (Chic.), 16, 512.

Banker, B. Q., Victor, M., and Adams, R. D. (1957). Arthrogryposis multiplex due to congenital muscular dystrophy. Brain, 80, 319.

Bargeton, E., Nezelof, C., Guran, P., and Job, J. C. (1961). Étude anatomique d'un cas d'arthrogrypose multiple congénitale et familiale. Rev. neurol., 104, 479.

Blattner, R. J. (1966). Arthrogryposis multiplex congenita. 7 . Pediat., 68, 823.

Brandt, S. (1947). A case of arthrogryposis multiplex congenita. Acta paediat. (Uppsala), 34, 365.
James, T. (1951). Multiple congenital articular rigidities. Edinb. med. . ., 58, 565.

Kanof, A., Aronson, S. M., and Volk, B. W. (1956). Arthrogryposis, a clinical and pathological study of three cases. Pediatrics, 17, 532.

Katzeff, M. (1943). Arthrogryposis multiplex congenita. Arch. Surg., 46, 673.

Moncrieff, A., and Wiles, P. (1934). Amyoplasia congenita. Proc. roy. Soc. Med., 27, 1001.

Swinyard, C. A. (1960). Progressive muscular dystrophy and atrophy and related conditions. Pediat. Clin. N. Amer., 7, 703.

Thamdrup, E. (1955). A case of arthrogryposis multiplex congenita. Acta paediat. (Uppsala), 44, 95.

Vestermark, B. (1966). Arthrogryposis multiplex congenita: a case of neurogenic origin. ibid., $55,117$.

\section{Addendum}

Since this paper was sent for publication, Amick, Johnson, and Smith (1967) reported that in 9 out of 10 consecutive cases of arthrogryposis, examined by them, the electromyographic and histological findings were consistent with neurogenic muscular atrophy (denervation). 